\title{
ECTOPARASITES OF THE BATS FROM KARST CAVES OF THE NATURE RESERVE «ICHALKOVSKY BOR» (NIZHNY NOVGOROD REGION)
}

(C) 2018

Fadeeva Galina Anatolievna, candidate of biological sciences, associate professor of Botany and Zoology Department

Boryakova Elena Evgenievna, candidate of biological sciences, associate professor of Botany and Zoology Department

National Research Lobachevsky State University of Nizhny Novgorod (Nizhny Novgorod, Russian Federation)

Abstract. The fauna of parasitic mites of bats from the karst caves in the region of the Volga Upland was studied in 2004-2005. Six species of bats such as Daubenton's water bat, Brandt's bat, whiskered bat, pond bat, northern bat and long-eared bat were examined. 18 species of arthropods were detected, among them there are gamasid mites (10 species) and harvest mites (2 species). Leptotrombidium russicum (Oud., 1902) and Myotrombicula sp. were found for the first time in Central Russia. Spinturnix acuminatus (Koch, 1836), Steatonyssus spinosus (Willmann, 1936), Steatonyssus periblepharus (Kolenati, 1858), Macronyssus flavus (Kolenati, 1856) turned out to be the main group of parasites in this study. As for the insects flies of the family Nycteribiidae and fleas of the family Ischnopsyllidae were found. The cluster analysis of ectoparasite fauna has showed that they are more or less evenly distributed among all members of mixed colonies of bats, while there is no violation of specificity in the choice of hosts. Low values of the Berger-Parker index marked a lack of competition between species, which indicates the stability of parasitic communities formed on bats in mixed colonies and in natural habitats. This fact indicates a complex relationship between the parasites in the community on the one hand, and long-term existence of the community on the other hand. This, in its turn, shows that in long-evolving communities competitive relationships between parasites are obliterated, which gives them stability. Herewith the bat colony is used as an integral whole, although some parasitic species prefer certain types of hosts.

Keywords: bats; parasitic mites; Gamasinae; Spinturnicidae; Nycterebiidae; fauna of ectoparasite; karst caves; Nizhny Novgorod Region; Volga Upland; cluster analysis; stability of parasite communities; Berger-Parker index; specificity of parasites to hosts.

\section{УДК 58.02}

DOI 10.24411/2309-4370-2018-14122

Статья поступила в редакцию 05.09.2018

\section{ПОДХОД К ОЦЕНКЕ СИНАНТРОПНЫХ СВОЙСТВ ВИДОВ}

(C) 2018

Федорова Любовь Валерьевна, старший преподаватель кафедры фармацевтического естествознания Первый Московский государственный медицинский университет имени И.М. Сеченова (2. Москва, Российская Федерация)

Купатадзе Галина Александровна, кандидат биологических наук, доцент кафедры ботаники Куранова Наталия Геннадиевна, кандидат биологических наук, доцент кафедры ботаники

Викторов Владимир Павлович, доктор биологических наук, профессор, заведующий кафедрой ботаники Московский педагогический государственньй университет (г. Москва, Российская Федерация)

Ежкова Валентина Геннадьевна, кандидат педагогических наук, доцент кафедры экономики, управления и бизнеса

Государственный гуманитарно-технологический университет

(2. Орехово-Зуево, Московская область, Российская Федераџия)

Аннотация. Обсуждается различие подходов к определению активности вида при фитоценотических и флористических исследованиях. Предложена формула для оценки синантропных свойств вида с учетом встречаемости и обилия вида в экотопах с различной антропогенной трансформацией. Проведен интегральный анализ синантропных свойств 32 видов травянистых растений флоры города Орехово-Зуево в 19 наиболее распространенных типах экотопов, относящихся к трем категориям антропогенной нарушенности. Выделено 6 групп видов как по экотопической, так и по синантропной пластичности. Обсуждается соотношение экотопической пластичности и синантропности видов. Показано, что синантропные свойства видов зависят от широты экотопической приуроченности видов, но не полностью с ней совпадают. Аборигенные виды с высоким индексом экотопической пластичности успешно осваивают разнообразные, в том числе и сильно трансформированные экотопы, и формируют факультативно синантропную составляющую локальной флоры, которая постоянна и независима от степени трансформации среды. Адвентивные виды, даже обладая высокой экотопической пластичностью, с большим трудом проникают в слабо нарушенные экотопы и по большей части остаются облигатными синантропами. Аборигенные виды обладают более высокой синантропной пластичностью. Выявлен сходный диапазон варьирования индексов экотопической и синантропной пластичности у условно синантропных и несинантропных видов, что указывает на лабильность границ этих групп.

Ключевые слова: урбанофлора; синантропные свойства видов; степень синантропности; несинантропные виды; условно синантропные виды; факультативно синантропные виды; облигатно синантропные виды; индекс представленности; индекс пластичности; экотопическая пластичность; синантропность видов; город Орехово-Зуево. 


\section{Введение}

В настоящее время существуют разнообразные подходы к изучению видов, приуроченных к антропогенно нарушенным территориям. Один из подходов, основанный на работах Я. Яласа [1] - изучение гемеробии как отношения видов к суммарному антропогенному воздействию [2-6]. Другие подходы связаны с выявлением приуроченности видов урбанофлор к городскому зонированию [7] или степени синантропизации флор [8]. Однако явление синантропности важно рассматривать не только на уровне флористических множеств, но и изучая синантропные свойства отдельных видов, в связи с их экологическим потенциалом. Применение методов, основанных на интегрировании нескольких однонаправленных показателей, связанных с адаптацией растений к антропогенным факторам, позволяет исследовать это явление на более высоком уровне разрешения.

Количественные методы интегральной оценки видов широко используются в фитоценологии. Одним из первых опытов подобной оценки стал предложенный Т.Э. Фрейем [9] «показатель значимости вида», а также индекс FCW, где F - встречаемость, C - степень постоянства, W - вес надземных частей. Таким образом Т.Э. Фрей решал задачу выявления роли того или иного вида в растительном сообществе. Для оценки доминирования вида Т.Э. Фрей [9] предложил формулу коэффициента доминирования $q=$ cd. Коэффициент доминирования (q) выводится из произведения количества доминирующих ценопопуляций (d) и общего количества ценопопуляций вида (c) в изучаемом сообществе. Впоследствии создалось целое направление в фитоценологии, занимающееся разработкой разнообразных количественных методов оценки видов в сообществах [10].

Количественные методы в отечественной флористике стали использоваться после введения Б.А. Юрцевым понятия активности вида $[11 ; 12]$. Смещение оценки с «фитоценотической» значимости вида на его «преуспевание» положило начало экотопологическому направлению в сравнительной флористике, при котором виды рассматриваются не как средообразователи, а как средопользователи. Активными видами Б.А. Юрцев считал преуспевающие элементы флоры, противопоставляя их реликтовым составляющим. Активность видов отражается в численности популяций, широте экологической амплитуды, равномерности расселения в пределах ареала.

Были предложены различные способы количественного определения активности вида, использующие интегрирование нескольких параметров. Так, Л.И. Малышев [13] рассчитывал активность вида на основе показателей встречаемости и обилия. Н.Г. Ильминских [14] определял активность вида на основании суммирования произведений проективного покрытия на количество описаний, в которых вид имеет фоновый процент проективного покрытия. Развивая идеи .А. Юрцева, Я.П. Дидух [15; 16] предложил учитывать три критерия: эколого-ценотическую амплитуду вида, степень его постоянства и проективное покрытие. Активность выражалась словесной формулировкой, например: «особо активные - эвритопные, с 4-5 классом постоянства и более 50\% покрытием». Идеи Я.П. Дидуха используются в настоящее время рядом исследователей [17-19]. Включение третьего критерия - экологической амплитуды - позволило сделать еще один шаг в сторону смещения акцента в понимании активности вида с ценотического на экологический. М.П. Наткевичайте-Иванаускене [20] подчеркивала возможность использования оценки флористической значимости видов в ценозах при анализе экотопологически гетерогенных локальных флор.

\section{Материал и методика исследования}

Для флористической оценки вида важны его экологические характеристики, которые опосредованно свидетельствуют о его потенциях. Ценотическая и экологическая успешность вида совпадают в наименее нарушенной среде, но по мере усиления ее трансформации показатели начинают расходиться, что особенно актуально для синантропных видов. Расхождение отражается в комплементарности вида его среде обитания, проявляющейся в осваиваемых видом экотопах. При указании на положение вида в пространстве (топ) во флористических исследованиях мы предпочитаем использование термина «экотоп», в понимании его как «местообитание», тогда как для обозначения среды обитания сообщества лучше подходит термин «биотоп» [21].

Степень антропогенной трансформации освоенных видом экотопов может быть показателем его синантропности, а широта охвата им экотопов различной степени трансформации свидетельствует об экологических потенциях вида по отношению к антропогенным факторам. Численность популяции вида в трансформированных экотопах также находится в прямой зависимости от его синантропных потенций. Интегрирование по вышеуказанным параметрам, действующим в одном направлении, может стать инструментом оценки свойств синантропности отдельных видов и их совокупностей.

В пределах флоры оценка вида по встречаемости и обилию с учетом зафиксированных экотопов может быть выражена отношением $\frac{a}{n} \cdot \frac{\sum D}{a}=\frac{\sum D}{n}$, где «n» обозначает общее количество экотопов, выявленных в исследуемой флоре, а «а» - количество экотопов, на которых зафиксирован изучаемый вид. При оперировании целыми единицами - экотопами - площадь охвата становится несущественной, так как экотопы выделяются по совокупности условий, а не по занимаемой ими площади, в этом случае показатель численности D всегда будет достоверным. Численность, вслед за Л.И. Малышевым, мы выражаем через обилие, градуированное по шкале Друде с переводом ее словесного выражения в цифровое (от un (1) до soc (7)). Если за «n» принять однотипные экотопы, то мы получаем Индекс представленности $(R)$ вида, что указывает на соответствие данного типа экотопов потребностям вида. Его можно выразить как $R=\frac{\sum D}{n(\mathrm{st})}$, где $\mathrm{R}$ - представленность (representation), n(st) - число исследованных однотипных экотопов (от same type - однотипность). В нашем случае под однотипными мы понимаем экотопы с равной степенью нарушенности. При объедении экотопов по выраженности в них какого-то одного фактора можно судить о приспособленности вида к этому фактору. Это применимо и к факторам, связанным с ан- 
тропогенным воздействием на среду. Можно сформировать группы по факторам вытаптывания, вспашки, засоренности и т.д. Индекс приспособленности будет фиксировать степень адаптации вида к соответствующему фактору. Наконец, если объединить экотопы с разными антропогенными факторами воздействия, то можно вычислить Индекс экотопической пластичности $(P)$, дающий представление о широте экологической амплитуды вида по отношению к комплексу учтенных факторов. Индекс пластичности можно представить как $P=\frac{\sum D}{n \text { (div) }}=R_{I}+R_{\text {II }}+R_{\text {III }}$, $\mathrm{P}$ - пластичность, n(div) - сумма разнообразных (разнотипных) экотопов.

Понятие экотопической пластичности введено для оттенения специфики приспособляемости видов к антропогенным факторам, трансформирующим природную среду. В этом пластичность отличается от толерантности, которая связана с потенциями видов по отношению к абиотическим факторам. Экотопы, выявленные на изучаемой территории в пределах естественных границ города Орехово-Зуево, распределены по трем категориям трансформированности с учетом силы и характера антропогенного воздействия на почвенный покров [9]. Сумма индексов представленности по всем трем категориям равна индексу экотопической пластичности вида P = RI + RII + RIII. Введение повышающего коэффициента для индекса представленности по экотопам второй и третий степеней антропогенной трансформации даст характеристику синантропной пластичности вида $\mathrm{P}(s y n)=\mathrm{RI}+2 \mathrm{RII}+3 \mathrm{RIII}$, где RI - представленность в разных экотопах первой, самой слабо-трансформированной категории, RII - представленность в средне-трансформированных экотопах, RIII - представленность в сильно-трансформированных экотопах.

При флористических исследованиях на территории города Орехово-Зуево выделено 50 типов экотопов и проведена их классификация по градиенту антропогенной нагрузки, а также совокупности лимитирующих факторов. Главные направления антропогенной нагрузки связаны как с прямым воздействием на почвенный покров: вытаптывание, съем и перемещение почвенных слоев (вспашка, перекапывание, рыхление), засорение, выпас, выкашивание, выем торфа и др., так и с опосредованным, через увеличение интродукции видов и т.д. По основным факторам трансформации почвенного покрова все выявленные экотопы сгруппированы в пять рядов по вектору усиления воздействия фактора/факторов и выделено три категории по степени нарушенности экотопов [21].

Из 460 видов травянистых растений флоры Орехово-Зуево для интегрального анализа выбрано 32 вида из разных семейств и представляющих весь спектр по степеням синантропности: несинантропные (встречаются преимущественно в первой категории экотопов), условно синантропные (встречаются в первой и во второй категориях), факультативно синантропные (осваивают все три категории экотопов), облигатно синантропные (встречаются в третьей и отчасти во второй категориях). Статус каждого вида, определенный ранее в результате маршрутных исследований в пределах 50 типов экотопов, отмеченных в городе Орехово-Зуево, не всегда соответ- ствует их статусу в выборке из 19 экотопов, задействованных в интегральном анализе. Хотя были представлены все категории экотопов по нарушенности [21], однако спектр экотопов, освоенных некоторыми выбранными видами, более широкий. Ограничение количества видов тридцатью двумя, а количества типов экотопов - девятнадцатью связано, с одной стороны, с трудоемкостью работы, с другой стороны - с необходимостью наличия определенного числа повторностей однотипных экотопов. Число обследованных повторностей указано в скобках.

1. Экотопы со слабой степенью нарушенности (I категория) - «лесопосадка» (2), «березняк» (5), «сосняк» (6), «дубрава» (3), «черноольшанник» (3), «берег» (3), «болото» (6), «луг» (7), «поляна» (12).

2. Экотопы со средней степенью нарушенности (II категория) - «обочина мелкоземистая» (6), «пустырь» (8), «стадион» (4), «газон» (4), «залежь» (2).

3. Экотопы с сильной степенью нарушенности (III категория) - «ж.-д. насыпь» (8), «клумба» (10), «поле» (3), «двор» (4), «свалка» (4).

Однотипными считались максимально сходные, но изолированные друг от друга экотопы, имеющие свои границы и разделенные другими экотопами. Разные газоны, поляны, клумбы и т.д. считались повторностями однотипных экотопов. В каждой повторности всех типов экотопов определялись обилие и (как вспомогательный параметр) проективное покрытие для выбранных видов. Индекс представленности вычислялся для каждого вида в пределах числа повторностей однотипных экотопов и затем для всех повторностей всех типов экотопов одной и той же категории по степени трансформированности. В дальнейшем сопоставлялись индексы представленности по разным категориям экотопов и суммы индексов, соответствующие пластичности видов по отношению к антропогенным факторам. В качестве примера приведем данные по трем из пятнадцати видов, обнаруженных в десяти повторностях экотопа «клумба». «Клумба» представляет собой небольшую территорию, засаживаемую однолетними цветами, где основными антропогенными факторами являются ежегодная перекопка, прополка и внесение питательного грунта и минеральных удобрений. Erigeron canadensis обнаружен на четырех клумбах в обилии $2,2,3,3$. Его индекс представленности в этом типе экотопов $R_{\text {клумба }}=10 / 10=1$, общий индекс по третьей категории экотопов RIII = 0,66; определяемая по сумме индексов всех трех категорий экотопическая пластичность $\mathrm{P}=0,04+0,25+0,66=0,95$. Chenopodium album найден на семи клумбах в обилии $3,3,2,3,3,2,3 ; \quad \mathrm{R}_{\text {клумба }}=19 / 10=1,9 ; \quad \mathrm{RIII}=1,48 ;$ $\mathrm{P}=0,15+0,71+1,48=2,34$. Erysimum cheiranthoides выявлен также на семи клумбах, но в большем обилии $3,3,3,3,4,3,3 ; \quad \mathrm{R}_{\text {клумба }}=22 / 10=2,2 ; \quad \mathrm{RIII}=1$; $\mathrm{P}=0,11+0,04+1=1,15$. При этом с учетом повышающего коэффициента самой высокой синантропной пластичностью также обладает Chenopodium album $(6,01)$, низкой Erigeron canadensis $(2,52)$.

\section{Результаты исследований и их обсуждение}

Численное значение индексов носит относительный характер и действует только в пределах выше обозначенной совокупности экотопов. Тем не менее 
определенные выводы об алгоритмах поведения видов можно сделать. Одни виды встречаются во многих экотопах в большом обилии, другие демонстрируют большое обилие в определенном количестве экотопов, третьи - в небольшом обилии во многих экотопах, четвертые - в небольшом обилии в малом числе экотопов. Естественно, что пластичные виды могут осваивать разнообразные экотопы, в которых хорошо себя чувствуют и поддерживают численность популяций на высоком уровне. Приспособленность видов к антропогенно измененным, порой очень жестким условиям существования, связана с особыми свойствами вида, их синантропностью, которая не всегда полностью совпадает с экотопической пластичностью. Результаты работы представлены в таблицах $1,2$.

таблица 1 - Представленность и экотопическая пластичности исследованных видов

\begin{tabular}{|c|c|c|c|c|c|c|c|}
\hline $\begin{array}{c}\text { № } \\
\Pi / \\
\Pi\end{array}$ & $\begin{array}{c}\text { Группы } \\
\text { и подгруппы } \\
\text { видов } \\
\text { по Индексу } \\
\text { пластичности }\end{array}$ & Виды & $\begin{array}{c}\text { Степень } \\
\text { синан- } \\
\text { троп- } \\
\text { ности }\end{array}$ & $\begin{array}{c}\text { Представ- } \\
\text { ленность } \\
\text { в экотопах } \\
\text { I катего- } \\
\text { рии } \\
\text { (RI) }\end{array}$ & $\begin{array}{c}\text { Представ- } \\
\text { ленность } \\
\text { в экотопах } \\
\text { II катего- } \\
\text { рии } \\
\text { (RII) }\end{array}$ & $\begin{array}{c}\text { Представ- } \\
\text { ленность } \\
\text { в экотопах } \\
\text { III катего- } \\
\text { рии } \\
\text { (RIII) }\end{array}$ & $\begin{array}{l}\text { Экотопи- } \\
\text { ческая } \\
\text { пластич- } \\
\text { ность } \\
\text { (Р) }\end{array}$ \\
\hline 1 & \multirow{5}{*}{$\begin{array}{c}\text { I а - } \\
\text { минимальная } \\
\text { пластичность }\end{array}$} & Bidens frondosa $\mathrm{L}$. & $\mathrm{OC}$ & 0 & 0 & 0,07 & 0,07 \\
\hline 2 & & Heracleum sibiricum L. & $\mathrm{YC}$ & 0,06 & 0,04 & 0 & 0,10 \\
\hline 3 & & Geranium pratense L. & $\mathrm{YC}$ & 0 & 0,13 & 0 & 0,13 \\
\hline 4 & & $\begin{array}{l}\text { Knautia arvensis } \\
\text { (L.) J.M. Coult. }\end{array}$ & $\mathrm{HC}$ & 0,13 & 0 & 0 & 0,13 \\
\hline 5 & & $\begin{array}{l}\text { Potentilla erecta } \\
\text { (L.) Rausch. }\end{array}$ & $\mathrm{yc}$ & 0,10 & 0,13 & 0 & 0,23 \\
\hline 6 & \multirow{5}{*}{$\begin{array}{c}\text { I б - } \\
\text { очень } \\
\text { малая } \\
\text { пластичность }\end{array}$} & Solanum nigrum L. & $\mathrm{OC}$ & 0 & 0 & 0,24 & 0,24 \\
\hline 7 & & $\begin{array}{l}\text { Silene vulgaris } \\
\text { (Moench) Garcke }\end{array}$ & $\Phi C$ & 0,11 & 0 & 0,14 & 0,25 \\
\hline 8 & & Hypericum perforatum L. & $\mathrm{yC}$ & 0,13 & 0,13 & 0 & 0,26 \\
\hline 9 & & Gallium mollugo L. & $\mathrm{HC}$ & 0,26 & 0 & 0 & 0,26 \\
\hline 10 & & Melampyrum pratense L. & $\mathrm{HC}$ & 0,34 & 0 & 0 & 0,34 \\
\hline 11 & \multirow{4}{*}{\begin{tabular}{|c} 
\\
I в - \\
малая \\
пластичность
\end{tabular}} & Chelidonium majus L. & $\Phi C$ & 0,15 & 0,27 & 0,10 & 0,52 \\
\hline 12 & & Galinsoga parviflora Cav. & $\mathrm{OC}$ & 0 & 0,08 & 0,45 & 0,53 \\
\hline 13 & & $\begin{array}{l}\text { Chamaenerion angustifoli- } \\
\text { um (L.) Scop. }\end{array}$ & $\mathrm{yc}$ & 0,47 & 0 & 0,07 & 0,54 \\
\hline 14 & & $\begin{array}{l}\text { Velarum officinale } \\
\text { (L.) Reichenb. }\end{array}$ & $\mathrm{OC}$ & 0 & 0,38 & 0,24 & 0,62 \\
\hline 15 & \multirow{5}{*}{$\begin{array}{c}\text { I д - } \\
\text { средняя } \\
\text { пластичность }\end{array}$} & Ranunculus repens L. & $\Phi C$ & 0,38 & 0,21 & 0,07 & 0,66 \\
\hline 16 & & Leontodon autumnalis L. & $\mathrm{OC}$ & 0 & 0,46 & 0,28 & 0,74 \\
\hline 17 & & Geum urbanum L. & $\Phi C$ & 0,32 & 0,21 & 0,24 & 0,77 \\
\hline 18 & & Sonchus oleraceus L. & $\mathrm{OC}$ & 0 & 0,13 & 0,66 & 0,79 \\
\hline 19 & & Poa annua $\mathrm{L}$. & $\mathrm{OC}$ & 0 & 0,50 & 0,31 & 0,81 \\
\hline 20 & \multirow{6}{*}{$\begin{array}{c}\text { II группа видов - } \\
\text { довольно } \\
\text { большая } \\
\text { пластичность }\end{array}$} & Impatiens parviflora DC. & $\mathrm{OC}$ & 0,04 & 0,58 & 0,28 & 0,90 \\
\hline 21 & & Aegopodium podagraria $\mathrm{L}$. & $\Phi C$ & 0,23 & 0,33 & 0,38 & 0,94 \\
\hline 22 & & Erigeron canadensis L. & $\mathrm{OC}$ & 0,04 & 0,25 & 0,66 & 0,95 \\
\hline 23 & & Tussilago farfara $\mathrm{L}$. & $\Phi C$ & 0,11 & 0,58 & 0,31 & 1,00 \\
\hline 24 & & Erysimum cheiranthoides L. & $\Phi C$ & 0,11 & 0,04 & 1,00 & 1,15 \\
\hline 25 & & Arctium tomentosum Miller. & $\mathrm{OC}$ & 0 & 1 & 0,38 & 1,38 \\
\hline 26 & \multirow{3}{*}{$\begin{array}{c}\text { III группа видов - } \\
\text { большая } \\
\text { пластичность }\end{array}$} & Trifolium pratense $\mathrm{L}$. & $\Phi C$ & 0,30 & 0,96 & 0,38 & 1,64 \\
\hline 27 & & $\begin{array}{l}\text { Polygonum aviculare } \\
\text { L.s.str. }\end{array}$ & $\mathrm{OC}$ & 0 & 1,04 & 0,72 & 1,76 \\
\hline 28 & & Chenopodium album L. & $\Phi C$ & 0,15 & 0,71 & 1,48 & 2,34 \\
\hline 29 & $\begin{array}{c}\text { IV группа видов - } \\
\text { очень большая } \\
\text { пластичность }\end{array}$ & Festuca pratensis Huds. & $\Phi C$ & 1,47 & 0,92 & 0,14 & 2,53 \\
\hline 30 & \multirow{2}{*}{$\begin{array}{c}\text { V группа видов - } \\
\text { чрезвычайно } \\
\text { большая } \\
\text { пластичность }\end{array}$} & Plantago major L. & $\Phi C$ & 0,32 & 1,96 & 0,97 & 3,25 \\
\hline 31 & & Urtica dioica $\mathrm{L}$. & $\Phi C$ & 1,02 & 1,63 & 0,66 & 3,31 \\
\hline 32 & $\begin{array}{c}\text { VI группа видов - } \\
\text { максимальная } \\
\text { пластичность }\end{array}$ & Taraxacum officinale Wigg. & $\Phi C$ & 0,85 & 2,63 & 1,24 & 4,72 \\
\hline
\end{tabular}

Примечание. $Н C$ - несинантропный, УC - условно синантропный, $Ф С-$ факультативно синантропный, $O C$ - облигатно синантропный. 
Таблица 2 - Сравнение экотопической и синантропной пластичности исследуемых видов

\begin{tabular}{|c|c|c|c|c|c|}
\hline $\begin{array}{l}\text { № } \\
\Pi / \Pi\end{array}$ & $\begin{array}{c}\text { Группы видов } \\
\text { по индексу } \\
\text { синантропной } \\
\text { пластичности }\end{array}$ & Виды & $\begin{array}{c}\text { Экотопическая } \\
\text { пластичность }\end{array}$ & $\begin{array}{c}\text { Синантропная } \\
\text { пластичность } \\
\text { (P(syn) }\end{array}$ & $\begin{array}{c}\text { Изменение } \\
\text { ранжиро- } \\
\text { вания }\end{array}$ \\
\hline 1 & \multirow{2}{*}{$\begin{array}{c}\text { I группа } \\
\text { видов } \\
\end{array}$} & Knautia arvensis (L.) J.M. Coult. & 0,13 & 0,13 & -3 \\
\hline 2 & & Heracleum sibiricum L. & 0,10 & 0,14 & 0 \\
\hline 3 & & Bidens frondosa $\mathrm{L}$. & 0,07 & 0,21 & +2 \\
\hline 4 & & Geranium pratense L. & 0,13 & 0,26 & -1 \\
\hline 5 & & Gallium mollugo L. & 0,26 & 0,26 & -4 \\
\hline 6 & & Potentilla erecta (L.) Rausch. & 0,13 & 0,26 & -1 \\
\hline 7 & & Melampyrum pratense $\mathrm{L}$. & 0,34 & 0,34 & -3 \\
\hline 8 & & Hypericum perforatum L. & 0,26 & 0,39 & 0 \\
\hline 9 & & Silene vulgaris (Moench) Garcke & 0,25 & 0,53 & +2 \\
\hline 10 & & Solanum nigrum L. & 0,24 & 0,72 & +4 \\
\hline 11 & & Chamaenerion angustifolium (L.) Scop. & 0,54 & 0,68 & -2 \\
\hline 12 & & Chelidonium majus L. & 0,52 & 0,97 & +1 \\
\hline 13 & & Ranunculus repens $\mathrm{L}$. & 0,66 & 1,01 & -2 \\
\hline 14 & & Geum urbanum L. & 0,77 & 1,46 & -3 \\
\hline 15 & & Velarum officinale (L.) Reichenb. & 0,62 & 1,48 & +1 \\
\hline 16 & & Galinsoga parviflora Cav. & 0,53 & 1,51 & +4 \\
\hline 17 & \multirow{10}{*}{$\begin{array}{l}\text { II группа } \\
\text { видов }\end{array}$} & Leontodon autumnalis L. & 0,74 & 1,76 & +1 \\
\hline 18 & & Poa aпnиа $\mathrm{L}$. & 0,81 & 1,93 & -1 \\
\hline 19 & & Aegopodium podagraria $\mathrm{L}$. & 0,94 & 2,03 & -2 \\
\hline 20 & & Impatiens parviflora $\mathrm{DC}$. & 0,90 & 2,04 & 0 \\
\hline 21 & & Tussilago farfara $\mathrm{L}$. & 1,00 & 2,20 & -2 \\
\hline 22 & & Sonchus oleraceus L. & 0,79 & 2,24 & +4 \\
\hline 23 & & Erigeron canadensis L. & 0,95 & 2,52 & +1 \\
\hline 24 & & Arctium tomentosum Mill. & 1,38 & 3,14 & -1 \\
\hline 25 & & Erysimum cheiranthoides L. & 1,15 & 3,19 & +1 \\
\hline 26 & & Trifolium pratense $\mathrm{L}$. & 1,64 & 3,36 & 0 \\
\hline 27 & \multirow{2}{*}{$\begin{array}{c}\text { III группа } \\
\text { видов } \\
\end{array}$} & Festuca pratensis Huds. & 2,53 & 3,59 & -2 \\
\hline 28 & & Polygonum aviculare L.s. str. & 1,76 & 4,24 & +1 \\
\hline 29 & \multirow{3}{*}{$\begin{array}{l}\text { IV группа } \\
\text { видов }\end{array}$} & Chenopodium album L. & 2,34 & 6,01 & +1 \\
\hline 30 & & Plantago major $\mathrm{L}$. & 3,25 & 6,18 & 0 \\
\hline 31 & & Urtica dioica $\mathrm{L}$. & 3,31 & 6,26 & 0 \\
\hline \multicolumn{6}{|c|}{ V группа - не выявлено видов с индексов синантропной пластичности от 6,598 до 8,215 } \\
\hline 32 & $\begin{array}{c}\text { VI группа } \\
\text { видов }\end{array}$ & Taraxacum officinale Wigg. & 4,72 & 9,83 & 0 \\
\hline
\end{tabular}

Наибольший индекс экотопической пластичности среди изученных видов выявлен у Taraxacum officinale $(4,72)$, наименьший у Bidens frondosa $(0,07)$. Самым большим индексом синантропности $\mathrm{P}(\mathrm{syn})$ также обладает Taraxacum officinale $(9,83)$, минимальный P(syn) отмечен у Knautia arvensis $(0,13)$.

Внутри исследованной совокупности виды формируют агрегации. Более четко их дискретность проявилась при применении формулы Стерджесса [22; 23], которая позволяет уловить малозаметные гиатусы: $n \approx 1+\log _{2} N$ или $n \approx 1+3,322 \cdot \lg N$, где $\mathrm{n}-$ число групп, N - число единиц совокупности $n \approx 1+3.322 \cdot \lg 32=6,0001$ [22]. Совокупность разбивается на 6 групп как по признаку экотопической, так и синантропной пластичности. Объем групп уменьшается по мере возрастания индекса пластичности. Так, первая группа с малыми значением Р состоит из 19 видов, вторая - 6, третья - 3, четвертая - 1. В пятой группе два представителя, в шестой один. Сходная, но не идентичная картина, наблюдается по синантропной пластичности $\mathrm{P}(\mathrm{syn})$. Относительно малой синантропностью обладают 130
16 видов. Все они входят в первую группу по индексу экотипической пластичности. У трех видов (Sonchus oleraceus, Leontodon autumnalis, Роа аппиа), индекс синантропности выше пределов множества, ограниченного рамками первой группы $(0,13-1,747)$ и они оказались по индексу синантропности во второй группе. Учитывая то, что формула Стерджесса позволяет выявить гиатусы между группами, переход этих видов во вторую группу свидетельствует о скачкообразном характере возрастания их синантропных свойств на фоне относительно низкой экотопической пластичности.

Вторая группа по индексу экотопической пластичности с интервалом 0,845-1,62 включает шесть видов, а вторая группа по индексу синантропности с интервалом 1,76-3,36 включает десять видов: 3 вида, указанные выше из I группы, 6 видов из II группы и 1 вид Trifolium pratense переходят сюда из III группы по индексу пластичности. T. pratense лучше всего представлен в экотопах средней степени нарушенности (табл. 1) и может являться примером сбалансированного факультативного синантропа с невысокой синантропностью. 
Расхождение между проявлением синантропной и экотопической пластичности особенно наглядно демонстрируют группы с высокими индексами пластичности. Пластичность резко возрастает на границе между IV (Festuca pratensis, $\mathrm{P}=2,53$ ) и V группой (Plantago major, $\mathrm{P}=3,25$ ). Однако по индексам синантропности оба эти вида, а также Urtica dioica $(\mathrm{P}=3,31)$ оказываются в более низких категориях: $F$. pratensis - в третьей, а $P$. major и $U$. dioica - в четвертой. Они предпочитают менее трансформированные экотопы по сравнению с C. album (PIII, PsynIV), проявляющим более высокую синантропную потенцию. Смещение в проявлении синантропных свойств вида по отношению к его видовым потенциям (табл. 2) проявляется не только между группами, но также и внутри групп. Например, вид первой группы Gallium mollugo имеет отрицательное смещение (-4), a Solanum nigrum положительное $(+4)$. Плюсовой сдвиг свидетельствует о том, что вид успешно реализуется в антропогенно измененной среде, а виды с минусовым смещением испытывают трудности в освоении трансформированных экотопов, и их видовые потенции ориентированы на существование в экотопах, приближенных к природным.

Соотношения синантропной и экотопической пластичности раскрываются более наглядно при сопоставлении пар видов. F. pratensis $(\mathrm{P}=2,53)$ и $C$. album $(\mathrm{P}=2,34)$ сходны по экотопической пластичности, но они резко отличаются по синантропным свойствам. Это проявляется в их приуроченности к экотопам разных степеней нарушенности. Ch. album тяготеет к сильно нарушенным экотопам, а $F$. pratensis - к экотопам со слабой степенью нарушенности. F. pratensis отмечена в таких экотопах I категории, как «березняк» $(\mathrm{R}=1)$, «луг» $(\mathrm{R}=2,86)$, «поляна» $(\mathrm{R}=3,56)$, общий индекс представленности $\mathrm{RI}=1,47$. Во II категории экотопов овсяница присутствовала в четыpex типах экотопов («пустырь», «стадион», «газон», «залежь»), но с меньшим обилием и более редкой встречаемостью (RII =0,92). Из пяти типов экотопов III категории вид обнаружен лишь в экотопе «двор» $(\mathrm{RIII}=0,14)$. Ch. album, напротив, хорошо представлен в экотопах III категории $(\mathrm{RIII}=1,48)$. Вид отмечен в четырех типах экотопов. Во II категории $C h$. album отмечен в двух типах экотопах: «обочина мелкоземистая» $(\mathrm{R}=1,33)$ и «пустырь» $(\mathrm{R}=1,13)$, представленность по II категории $\mathrm{RII}=0,71$. В I категории экотопов вид удалось обнаружить только в «березняке» и «лесопосадке» с низкой встречаемостью и обилием $(\mathrm{RI}=0,15)$. Сравнивая эти виды, можно предположить, что высокая экотопическая пластичность $F$.pratensis позволяет ей осваивать сильно трансформированные экотопы, оставаясь по своей природе несинантропным видом. Наоборот, высокая экотопическая пластичность способствует внедрению синантропного вида Ch. album в слабо нарушенные экотопы. Все виды четвертой, пятой и шестой групп с высоким индексом пластичности - факультативно синантропные виды, способные осваивать экотопы всех трех категорий нарушенности. Однако одни предпочитают менее, а другие более нарушенные экотопы. Исключением является Polygonum aviculare, который, обладая довольно высокой пластичностью $(\mathrm{P}=1,76)$, не был отмечен в экотопах I категории. Интересная особенность этого вида состоит в том, что он обнаружен далеко не во всех повторно- стях однотипных экотопов. Однако обилие популяций везде, где он растет, было очень высоким. Низкая встречаемость в сочетании с высоким обилием следствие жизненной стратегии P. aviculare, проявляющейся в существовании в виде куртин.

Три вида II группы по индексу пластичности имеют близкие значения: Impatiens parviflora $(\mathrm{P}=0,9)$, Aegopodium podagraria $(\mathrm{P}=0,94)$ и Erigeron canadensis $(\mathrm{P}=0,95)$. Наиболее близкими по индексу пластичности являются A. podagraria и E. canadensis а по индексу синантрпности - A. podagraria $($ Psyn $=2,03)$ и I. parviflora $(\mathrm{Psyn}=2,04)$. A. podagraria довольно равномерно распределена по всем категориям экотопов (0,23-0,33-0,38), a I. parviflora и E. canadensis в I категории экотопов присутствуют номинально. Их индексы представленности по I категории экотопов очень маленькие и одинаковые $(0,04)$, при этом максимум представленности I. parviflora фиксируется во II $(0,56)$, у E. canadensis в III категории экотопов $(0,66)$, т.е. мелколепестник обладает большей синантропностью по сравнению с недотрогой. Учитывая то, что оба эти вида являются адвентивными, можно предположить, что I. parviflora, осваивая экотопы средней степени нарушенности, лучше адаптировалась к местным условиям по сравнению с E. canadensis. Успешное освоение I.parviflora экотопов II категории дает ей лучшие перспективы для продвижения в экотопы I категории и, соответственно, в природные сообщества. Сравнение E. canadensis с аборигенным широко амплитудным видом - A. podagraria показывает, что чужеродному виду, даже обладающему довольно большой пластичностью, сложно осуществить внедрение в природные сообщества, в то время как местные виды с легкостью заселяют нарушенные местообитания, если им позволяет это сделать их видовой потенциал.

Наиболее многочисленная I группа видов включает представителей всех степеней синантропности. Некоторые виды выпадают из одной или даже двух категорий экотопов. Например, Bidens frondosa и Solanum nigrum не представлены в I и II категориях экотопов - это типичные облигатные синантропы. Galium molugo и Melampyrum pratense не обнаружены во II и III категориях. При этом статус этих видов, определенный в результате маршрутных исследований, различен. M. pratense - действительно несинантропный вид, а G. molugo - факультативно синантропный, он был встречен в экотопах II и III категории, которые не задействованы в интегральном анализе. В таком же положении находятся Knautia arvensis и Heracleum sibiricum, имеющие еще более низкую экотопическую пластичность. Эти виды можно назвать формально (неустойчиво) факультативными синантропами, кое-где прорывающимися в трансформированные сообщества, но их низкий экотопический потенциал не позволяет им быть полноценными обитателями экотопов II и особенно III категории. Настоящими факультативными синантропами с минимальной пластичностью являются $R a$ nunculus repens ( $\mathrm{RI}=0,38 ; \mathrm{RII}=0,21 ; \mathrm{RIII}=0,07)$ и Chelidonium majus $(\mathrm{RI}=0,15 ; \mathrm{RI}=0,27 ; \mathrm{RIII}=0,10)$, которые представлены во всех категориях экотопов.

При сопоставлении синантропных свойств растений выявилась небольшая группа факультативных синантропов, представленная одними и теми же видами на территориях с разной интенсивностью ан- 
тропогенной нагрузки. Так как данная группа стабильна и неизменна на территории локальной флоры и не зависит от степени нарушенности местообитаний, ее можно назвать «факультативной константой». Показано, что все виды, обладающие высокой экотопической пластичностью, - это факультативные синантропы, однако факультативными синантропами могу быть и умеренно пластичные виды. Даже в пределах небольшой выборки индекс экотопической пластичности у факультативно синантропных видов варьирует от 0,52 до 4,72. Кроме того, данная фракция не однородна и по синантропной пластичности. Одни виды имеют максимум представленности в экотопах третьей категории (Ch. album, E. cheiranthoides), другие предпочитают экотопы первой категории (F.pratensis, R. repens), половина видов отдают предпочтение экотопам второй категории. Aegopodium podagraria и Geum urbanum распределены примерно одинаково во всех категориях экотопах.

В отличие от факультативно синантропной фракции, состав других групп (ОС, УС, и НС) находится в зависимости от трансформации среды. Облигатно синантропные виды более разнообразны и обильны в сильно нарушенных местах (здесь же сосредоточено и большинство адвентиков), а условно синантропные и особенно несинантропные виды - в менее нарушенных природно-территориальных комплексах. Диапазон варьирования индексов экотопической пластичности у облигатно синантропных видов довольно большой $(0,07-1,76)$, большинство этих видов способны осваивать экотопы второй категории.

В связи с синантропной адаптацией важно сопоставить виды УС и НС фракций. К сожалению, в список, который составлялся до начала осуществления интегрального анализа, попало мало видов этих групп. Всё же некоторые предварительные предположения можно сделать. Диапазон варьирования индекса экотопической пластичности условно синантропных и несинантропных видов практически совпадают $(0,1-0,54$ и $0,13-0,34$ соответственно). Вторую категорию экотопов способны осваивать аборигенные виды с низкой экотопической пластичностью, иначе говоря, границы между категориями несинантропных и условно синантропных видов не лимитируется их пластичностью, но определяется их присутствием или отсутствием в экотопах второй категории. Можно предположить, что виды местной флоры довольно легко адаптируются к умеренно трансформированной среде и успешно конкурируют с адвентиками в экотопах второй категории. В сильно нарушенных экотопах стабилизирующую роль выполняют факультативно синантропные виды, которые конкурируют там с адвентивными видами. Кроме того, они имеют большое значение в восстановлении растительного покрова при демутационных процессах после снятия антропогенной нагрузки и по мере перехода среды обитания в исходное состояние, т.к. они способны существовать в широком диапазоне условий, связанных с большей или меньшей степенью нарушенности среды.

\section{Выводы}

Синантропность - свойство растений существовать в антропогенно измененной среде - зависит от потенциальной возможности видов адаптироваться к антропогенным факторам воздействия на среду. Ин- декс синантропности показывает эффективность видов в реализации синантропных свойств, что выражается в успешности их существования в трансформированной среде. Синантропность не всегда совпадает с экотопической пластичностью. Виды, имеющие сходную экотопическую пластичность, могут отличаться по синантропности. Исследованные нами виды формируют группы, в пределах которых наблюдается плавное изменение синантропных свойств.

Виды, проявляющие высокую экотопическую пластичность и входящие в 4-6 группы, являются факультативными синантропами, при этом виды с меньшим индексом экотопической пластичности также могут относиться к факультативно синантропной фракции. Минимальная экотопическая пластичность, обеспечивающая стабильное присутствие во всех трех категориях экотопов, выражается индексом 0,52. Данная фракция внутренне неоднородна и имеет различную представленность видов в экотопах трех выделенных категорий, таким образом, факультативно синантропные виды играют важную роль в восстановлении растительного покрова на территориях после снятия антропогенной нагрузки.

Индекс пластичности облигатно синантропных видов варьирует в наших исследованиях в пределах от 0,07 до 1,76. Как аборигенные, так и адвентивные виды этой фракции присутствуют в экотопах второй и третьей категории, но адвентики сосредоточены в сильно нарушенных экотопах, а аборигенные - в экотопах со средней степенью трансформации. Высокая синантропность подчас выступает помехой при освоении адвентивными видами естественных местообитаний со слабой нарушенностью, и они остаются облигатными синантропами, заселяя сильно трансформированные экотопы, куда, как правило, изначально и проникают, в то время как даже умеренно пластичные аборигенные виды способны адаптироваться к антропогенной нагрузке и могут осваивать нарушенные экотопы даже с высокой степенью трансформации.

Несинантропные и условно синантропные виды имеют сходный диапазон варьирования индекса экотопической пластичности и индекса синантропности, что свидетельствует о лабильности границ между этими двумя фракциями. Таким образом, в работе показаны некоторые аспекты приложения интегрального подхода к выявлению дискретности и изучению экотопической и синантропной стратегий отдельных видов. Использованный подход позволяет не только градуировать виды исследованной совокупности по степеням синантропности и проводить сравнение их свойств, но и более глубоко проникнуть в природу самого явления синантропности.

\section{Список литературы:}

1. Jalas J. Hemerobe und hemerochore Pflanzenarten. Ein terminologischer Reformersuch // Acta Societia Pro Fauna et Flora Fennica. 1955. Vol. 73. P. 1-15.

2. Ишмурзина М.Г., Барлыбаева М.Ш. Гемеробиальность синантропных и синантропизированных растительных сообществ Южно-Уральского заповедника // Вестник Удмуртского университета. Серия «Биология. Науки о Земле». Т. 25, вып. 2. 2015. C. $77-81$.

3. Kunick D. Zonietung des Stadtgebietes von Berlin (West). Ergebnisse Floristischer Untersuchung // Gen. 
Schriftenr. d.Fachber. Landschaftsentwicklung u. Umweltforsch. № 14. P. 1-164.

4. Frank D., Klotz S. Biologisch-oekologische Daten zur Flora DDR. Martin Luther Universitaet, HalleWittenberg, 1990. $167 \mathrm{~s}$.

5. Jackowiak B. The hemeroby concept in the evaluation of human influence on the urban flora of Vienna // Phytocoenisis. 1998. Vol. 10. P. 79-96.

6. Hill M.O., Roy D.B., Tompson K. Hemeroby, urbanity and ruderality: bioindicators of ditrurbance and human impact // Journal of Applied Ecology. 2002. Vol. 39, № 5. P. 708-720.

7. Wittig R., Diesing D., Gödde M. Urbanophob Urbanoneutral - Urbanophill. Das Verhalten der Arten gegenüber dem Lebensraum Stadt // Flora. 1985. № 177. P. 265-282.

8. Sudnik-Wojcikowska B. Studies on Indices of Flora Synanthropization // Flora. 1992. Vol. 187. P. 37-50.

9. Фрей Т.Э.-А. Некоторые аспекты фитоценотической значимости вида в растительном сообществе // Ботанический журнал. 1966. № 8. С. 1073-1084.

10. Жукова Л.А.Экологические шкалы и методы анализа экологического разнообразия растений. Йошкар-Ола: Марийский государственный университет, 2010. 368 c.

11. Юрцев Б.А. Флора Сунтар-Хаята. Л.: Наука, 1968. $236 \mathrm{c.}$

12. Юрцев Б.А. О количественной оценки «веса» видов при флористическом районировании // Ботанический журнал. Т. 68, № 9. 1983. С. 1145-1152.

13. Малышев Л.И. Флористическое районирование на основе количественных признаков // Ботанический журнал. Т. 58, № 11. 1973. С. 1581-1588.

14. Ильминских Н.Г. Понятие «активность видов» и его место среди методов изучения растительного покрова // Растительный покров антропогенных местообитаний: сб. науч. трудов. Ижевск, 1988. С. 25-36.

15. Дидух Я.П. Проблемы активности видов растений // Ботанический журнал. Т. 67, № 7. 1982. C. $925-935$.

16. Дидух Я.П. Анализ эколого-ценотической дифференциации растительного покрова горного Крыма // Ботанический журнал. № 8. 1988. С. 1168-1178.

17. Бабич Н.А., Ушакова С.Н. Активность видов сегетальной флоры питомников южнотаежной подзоны Вологодской области // Вестник Северного (Арктического) федерального университета. Серия «Естественные науки». Вып. 2. Архангельск, 2012. C. 5-10.

18. Коновалова И.С., Бабич Н.А., Марич С.Н. Фитоценотическая значимость сорных растений лесных питомников // Лесной журнал. 2014. № 1 (337). C. 37-45.

19. Раков Н.С. Состав, структура и динамика адвентивной флоры Ульяновской области: автореф. дис. ... канд. биол. наук. Тольятти, 2012. 19 с.

20. Наткевичайте-Иванаускене М.П. Количественные соотношения встречаемости и константности групп видов в растительных сообществах // Биологические науки. № 8. 1985. С. 63-68.

21. Федорова Л.В., Купатадзе Г.А., Куранова Н.Г., Викторов В.П. Классификация городских экотопов в связи с изучением синантропности (на примере города Орехово-Зуево) // Социально-экологические технологии. 2017. № 1. С. 52-63.

22. Василевич В.И. Статистические методы в геоботанике. М.: Наука, 1969. 232 с.

23. Статистика: учебно-практическое пособие / под ред. М.Г. Назарова. 2-е изд. стер. М.: КНОРУС, 2008. С. 26-33.

\section{THE INTEGRAL METHOD OF SPECIES SYNANTHROPIC PROPERTIES ASSESSMENT}

Fedorova Lyubov Valeryevna, senior lecturer of Pharmaceutical Natural Science Department I.M. Sechenov First Moscow State Medical University (Moscow, Russian Federation)

Kupatadze Galina Alexandrovna, candidate of biological sciences, associate professor of Botany Department Kuranova Natalya Gennadievna, candidate of biological sciences, associate professor of Botany Department Viktorov Vladimir Pavlovich, doctor of biological sciences, professor, head of Botany Department Moscow State University of Education (Moscow, Russian Federation)

Ezhkova Valentina Gennadievna, candidate of pedagogical sciences, associate professor of Economics, Management and Business Department University for Humanities and Technologies (Orekhovo-Zuevo, Moscow Region, Russian Federation)

Abstract. The paper discusses different approaches of species activity determination in phytocenotic and floristic studies. The authors propose a formula of representation and plasticity for estimating the properties of the species taking into account the occurrence and abundance of the species in ecotopes with different anthropogenic transformation. The study contains a comprehensive analysis of sinanthropy properties of 32 herbaceous plants species related to the flora of Orekhovo-Zuyevo in the 19 most common types of ecotopes of different categories of anthropogenic disturbance. All species form 6 groups according to the ecotopic and sinanthropic plasticity. The relationship between the ecotopic and sinanthropic plasticity is discussed. It is shown that the synanthropic properties of species depend on the plastisity, but do not completely coincide with it. Native species with a high plasticity index successfully master a variety of ecotopes, including highly transformed ones and form a facultative-synanthropic (FS) component of the local flora. This species complex in boarders of local flora is constant and independent of the degree of the environment transformation. Adventive species, even with a high plasticity, penetrate the undisturbed ecotopes with difficulty and for the most part remain obligate sinanthropes (OS). The lability of the borders between non sinanthropic (NS) and relatively sinanthropic (RS) groups lead to the transition from one species group to the other.

Keywords: sinanthropic properties of species; degree of sinanthropy; non sinanthropic species; relatively synanthropic species; facultative synanthropic species; obligate sinanthropic species; Index of representation; Index of plasticity; sinanthropic plasticity; Orekhovo-Zuyevo. 